\title{
Unconventional Roles and Activities Identified by Instructional Designers
}

\author{
Richard A. Schwier \\ Jay R. Wilson \\ University of Saskatchewan, Canada
}

\begin{abstract}
Students complete courses or entire programs in instructional design (ID) and enter the professional arena confident they are prepared to wrestle with the complexities and demands of ID. What many of those fresh to the profession discover is that in addition to applying what they learned in school, they are called upon to carry out a number of additional tasks, often in areas where they have no training or previous experience. This paper reports on the results of an investigation carried out with 22 instructional designers practicing in post-secondary institutions in Canada and the United States. The purpose was to reveal the aspects of professional practice that instructional designers felt were important, but that were outside the traditional boundaries and training of instructional design. Through focus groups and email discussions, we identified several roles that instructional designers described as important, but were peripheral to the traditional standards of practice and competencies in instructional design.
\end{abstract}

Keywords: Instructional design; ID; Professional practice; Experience; Interviews; Research

\section{Introduction}

Learning about instructional design (ID) conventionally emphasizes the study and application of systems to create learning products. Learning about ID includes exposure to design models, various types of skill development, and achievement of a generally accepted set of competencies (IBSTPI, 2000: Richey, Fields \& Foxon, 2001). The International Board of Standards for Training, Performance and Instruction (IBSTPI, 2000) lists four categories of competencies: professional foundations, planning and analysis, design and development, and implementation and management. Most of the competencies identified by IBSTPI refer to the technical or process skills that an instructional designer must demonstrate to be successful. In 2006, IBSTPI commented on the fact that many large universities in the US are moving to this set of competencies as the guiding beacon for their ID programs. Similarly, Dooley, Lindner, Moore, Telg, Irani, and Lundy (2007) developed a set of competencies specific to the Roadmap to Success Program. They identified seven categories of competencies for instructional designers: needs assessment, writing objectives, choosing content and method, choosing delivery strategies, assessment, roles of a development team, and best practices. 
Conventionally, a program in instructional design takes students through the steps to develop an understanding of ID. University ID programs address essential skills to allow students to function as novice instructional designers. Educational institutions appear to adopt similar content teaching instructional design. In many well-respected and widely adopted ID textbooks, systems and skills are stressed, even while acknowledging the complexity, diversity and context-dependent nature of ID practice (e.g., Dick, Carey, \& Carey, 2009; Morrison, Ross, \& Kemp, 2010; Smith \& Ragan, 2004). At the same time, programs are creating a variety of approaches to teaching instructional design, from studio-based integrated courses to experiential and authentic learning environments, and approaching the idea of design from multiple perspectives (Boling, Gibbons, Ertmer, Schwier, \& Wilson, 2009; Jonassen, Boling, Gibbons, Parish, \& Schwier, 2008).

Despite the successes and satisfactions experienced by students, and an apparent consensus around what competencies are important, there appear to be a number of skills that are not addressed in these lists of competencies or in formal ID programs-skills that are discovered by instructional designers after they enter the field, and sometimes long after their formal education has been completed (Schwier, Campbell, \& Kenny, 2007). This implies that there may be topics that are neglected in instructional design programs that deserve attention. This study was an attempt to begin exploring the unanticipated roles and skills instructional designers identify in their practice of ID.

The question we pose in this study is, "What skills, competencies and roles do instructional designers perform that they feel are outside the conventional expectations of instructional design?" Campbell, Schwier and Kenny (2009) investigated instructional designers as agents of social change. One early product of that research program explored what instructional designers do in practice (Kenny, Zhang, Schwier, \& Campbell, 2005), which had already attracted some interest in the literature (Cox \& Osguthorpe, 2003; Gibbons, 2003; Gustafson \& Branch, 2002; Rowland, 1992). During the investigations by Kenny, et al., an interesting phenomenon, and perhaps a trend emerged. Individuals in instructional design positions often described what they do as "not really instructional design," despite some evidence that they were actually doing a host of activities that many would classify as legitimate instructional design activities. This raised the question of what it means to be an instructional designer and participate in the culture of instructional design. If instructional designers are doing things they interpret as outside of instructional design-sometimes predominantly-how does it change how they see themselves as professional practitioners of instructional design?

In this investigation, we assumed that practicing instructional designers would view their roles differently, depending on their own training, their institutional contexts and cultures, and their own predispositions to the profession. So the purpose of this investigation was not to create an exhaustive or definitive list of what instructional designers do that is not supposed to be part of their role, nor was the purpose to chastise professional educational programs in instructional design for ignoring significant content. Rather, the purpose was to uncover and consider the things that instructional designers found surprising or interesting as professional instructional designers - things they didn't anticipate, but which became important factors in the performance of their work, their satisfaction in their positions, and their professional identities. Another purpose was to interrogate our own teaching; when we prepare instructional designers, should we 
consider some of the topics that instructional designers suggest were neglected in their professional programs?

\section{Methodology}

This study was exploratory and descriptive in intent, so we employed an interpretive qualitative methodology. The data were gathered in two ways, by e-mail and through a focus group session. Twenty-two instructional designers in post-secondary institutions were invited to participate in the study. Twenty participants were from Western Canada and two were from the Midwestern United States. The selection criteria were that participants must have held a full-time instructional design position for at least two years in post-secondary education and must have earned an advanced degree with a concentration in instructional design.

The sample was a sample of convenience, essentially drawn from a list of colleagues who were identified by the researchers because they were acquainted with the individuals or their work. There was no attempt to identify a representative sample, nor was the group chosen to represent particular demographics such as age, gender or type of ID position. As a result, we make no claims about generalizing these findings. Rather, we offer them as selected observations readers can use to reconsider their own practice of instructional design or educational programs in instructional design.

Participants were given the choice of participating in either a focus group or by e-mail. Of the 22 individuals invited to participate in the study, 16 elected to participate by e-mail, and six elected to join a focus group conversation. The conversation with the focus group was held in one session of approximately two hours duration. A verbatim transcript of the conversation was produced for analysis. Written e-mail responses and the transcript of the focus group conversation were coded for instances where participants specifically commented on unconventional roles they played as instructional designers. Two people coded the transcripts, and a consensus approach was used to test reliability such that where there was disagreement between coders, the disparity was discussed. Where agreement was not achieved, those codes were eliminated. Researchers were looking for unique or interesting commentary, and so inter-coder reliability was addressed by negotiating agreement rather than testing for inter-rater reliability.

The e-mail group was asked:

When you are working on ID projects, what is it that you find yourself doing that you don't actually consider part of instructional design? Another way to look at this is, "What are some of the expectations people have of you that you didn't anticipate when you took a position or project as an instructional designer?

Similarly, the focus group was given this introduction to start a two-hour discussion:

We all think we know what instructional designers do, but you work with clients and in systems and organizations where you may find yourself doing things that don't seem like they are part of the instructional design 
process. I'd like you to talk about that... what it is first, but also about any satisfactions or frustrations that accompany these roles. Do you do anything that isn't strictly in the ADDIE model?

\section{Findings of the Study}

The responses were plentiful, clear and passionate. It was immediately evident that this was a question that instructional designers were eager to answer, and that also caused them some reflection and irritation. For the purpose of this paper key quotations from the e-mails and transcript of the focus group have been included (attributed to pseudonyms), and an attempt has been made to label the topics raised by participants. The labels describe some roles that are not dealt with significantly in our own literature, and may only be touched on in our professional programs of study, or by some universities and not others. At the same time, the labels are not unique to instructional design, and we observe that they could as easily apply to many servicebased professions in complex organizations.

\section{Professional Relationship Roles}

One of the first issues to become evident was the importance of being able to build productive professional relationships with a variety of individuals and in diverse contexts, particularly given the designer's primary responsibility to the design tasks, which are inextricably bound to the interpersonal relationships among partners (Solomonson, 2008). Certainly this is not an area that is unique to instructional design, and it is an expected skill set of designers clearly identified in existing standards (IBSTPI, 2000). Nevertheless, the participants communicated clearly that professional relationships were at the heart of their work, yet they felt that they were not sufficiently prepared for the interpersonal aspects of the work in their graduate training. Welldeveloped interpersonal skills are a necessity for understanding and communicating with the diverse personalities and situations that an instructional designer encounters almost daily. Being able to initiate short-term trusting relationships goes a long way in supporting the structure of the design project. Identifying when to press the client to produce or when to give the client or subject-matter expert (SME) time to reflect or to attend to professional demands outside of the project are also crucial relationship skills that are constantly being applied.

I build a relationship with the person first. So a lot of the initial work has nothing to do with instructional design. I give them little tasks; I get them comfortable; but it's basically having them learn to trust me. I mean it's really easy to say, when I walk into an instructional design process, [to think] that there's no emotion here. We're just going to take this pure physics content and we're going to turn it into a lovely physics course. But this is, of course, someone who's been passionate about this content for God knows how long, and they've been asked to do something they're fundamentally afraid of at some level. So it really is a trust issue as well as a physical process and making sure that we have the same language, and 
making sure that I'm able to translate what they're saying. But the trust has to be there first. (Dijan)

One of the confounding factors when building new client relationships is that subject matter experts (SME) are often required to join a project. New SMEs are especially vulnerable to workload assignments they might not understand. They enter a project with less confidence and perhaps less tenacity and enthusiasm than SMEs who initiate their own projects. The instructional designer is then challenged to be intuitive about the needs of the SME and build a relationship that is supportive and productive. In fact, one participant suggested that a major challenge of doing instructional design is making the subject matter expert appear to be successful.

99.9\% of the time we're working with first-time faculty. They've been told to come to this process. Many of them have no choice. The early adopters have long-gone. So they enter this whole new realm of how to do this with a confidence level equivalent to going to kindergarten for the first time. Because they have the content knowledge, they know exactly what is required, but this whole thing about technology, the relationship with students, being online, being on television, using a blended model, is really setting them back because they don't feel they walk into it with confidence. (Dijan)

You have to be a little bit intuitive when you're an instructional designer. And you get to know your SME, and you get to know in what ways this person is comfortable, and threatened, and what you have to do, basically, to make the person look good, because that's what the challenge of our job is. We not only get across what she wants to get across, but we also make her look good. (Rep)

The relationship issues that are a part of working with SMEs are often not anticipated by new instructional designers, and they reported that very little time was paid to the interpersonal aspects of their work in their ID programs. When a project is started, a novice instructional designer may feel confident that all those involved will approach the project with the same high level of commitment. Often times what is discovered is that the project does not have the same priority for the SME as it does for the instructional designer, and the designer has very little leverage to encourage greater commitment.

I've had some contracts where the SME didn't have a clue. Even with gentle prodding via e-mail, phone conversations, and team meetings, I've had some SMEs who did not provide enough content or content that addressed the specific learning requirements. I spent a great deal of time searching the Internet to find information to "fill in the gaps". I know it's not my role, but in the end, it was just quicker than trying to pry words out of an idiot. (Shap) 
I spend a ridiculous amount of time trying to get Subject Matter Experts to come through with content. When I'm desperate I'll call a meeting, sit down with the SME, and write the content with him right there. When a project stalls, more often than not it's because I'm waiting on a SME. (Pady)

Of course, this speaks to an authority disparity in the academy generally, a condition that is much broader on most campuses than merely with instructional design services. But instructional designers find themselves in frustrating positions where relationship building, organizational behaviour, persuasion, and motivation are important tool skills, and these are skills we seldom address in instructional design programs.

\section{Project Roles}

Much as a teacher needs to draw on a selection of appropriate tricks and skills, an instructional designer is often called on to serve a variety of roles in a project. An instructional designer is typically accountable for a wide array of responsibilities on a project and needs to be flexiblealmost chameleon-like-in order to respond to shifting demands. The instructional designer becomes the individual on the team who brings together the disparate, and sometimes discordant, demands of others on the team.

I have a friend who's an instructional designer, and he says, "Basically, I'm peanut butter in the peanut butter and jam sandwich." I hold the thing together. So it's a translator role; it's hearing what somebody is saying, you're trying to imagine how that might happen, you're relaying that to the media people who are going to help you to do that, and you're sort of the glue that holds it all together. (Kats)

Participants suggested that instructional designers needed to anticipate problems or react to situations as they arise. With an emphasis on completion and tight timelines, responsibility falls to the instructional designer to marshal team resources and move the project toward completion despite interruptions and obstacles.

I see myself as a problem-solver. Either I'm solving problems, or negotiating solutions to problems with someone else, and I do that so many times during the day. ADDIE is partly about solving problems, but it feels much more clean that what you actually end up doing, from dealing with political problems to how to get the videotapes to the students. (Rep)

Because all projects are different it is often difficult to anticipate every need, so an instructional designer must know when to call on specialists. Having these individuals on your team and recognizing when to call on them can rehabilitate or propel a project, a knack for prescience that grows with time and experience. 
Over time, I've learned that by just working with groups, some people have some talents that are way the heck out of their normal area of expertise that they can bring to the project. (Gap)

One of the unanticipated project roles reported by instructional designers is providing specific faculty development, often including training on tools and their affordances. Depending on the size and status of the organization an instructional designer may also be called on to provide technology support. Technology support may not be an official role or area of expertise but may become an important part of the relationship with the SME or instructor. Once the instructional designer has gained the trust of the instructor and maintained regular contact throughout a project, the instructional designer becomes a touchstone for a wide variety of requests and consultation with clients that extend beyond the life of course design, development, and initial evaluation. One participant spoke clearly about how the instructor sometimes became dependent on the designer, relying on them for advice and reassurance, and this reliance faded as the instructor gained experience with the instructional products.

I do more of this than I anticipated. Instructors sometimes consult with Technology Enhanced Learning when they can't figure something out or want ideas. This is an enjoyable part of the job. (Pady)

Getting the faculty member to know how to teach in this environment; that means, at least for the first time the course is offered, being there as a support, as a sounding board, [recommending] techniques and approaches they might try. They've trusted you to get [the course] up; now they need to trust you to get it through to the students. By the second time they've taught it, it's easier; by the third time, the only time I hear from my SME is when they want to go for coffee. (Dijan)

Project management figured prominently in our conversations with instructional designers. They were surprised at how important project management skills were, and they reported that they received little in the way of formal training in project management in their programs of study. Certainly this is an area that has been identified as an important professional competency (IBSTPI, 2000) and it is addressed in the literature on instructional design (Brill, Bishop, \& Walker, 2006; Correia, Yusop, Wilson, \& Schwier, 2010; Greer, 1994; Williams vanRooij, 2009). Keeping a project moving involves not just working with individuals and teams but includes dealing with the administrative aspects of the job as well. For an instructional designer, project management is an important component of completing a project on time and on budget. Designers may find that they are put in a similar situation as the clients who are flailing about in the project. Designers get requests from financial departments, human resources divisions, copyright agencies-all demanding information and accountability. These highly specialized skills are necessary for staff to be paid, content to be safeguarded, laws observed and employees to be monitored. These are among many skills that a designer may develop over time, but initially they can seem quite overwhelming, and later, responsibility for them may seem tedious.

I spend a lot of time on business-related duties, such as writing the contract, budgeting, assessing team members' strengths, and trying to 
anticipate possible problems. It's good experience, but much more business-oriented than I thought ID would be. (Pady)

It seems to fall to me to find someone to pay for stuff when nobody wants to. [A co-designer] and I have been talking a lot about a current project we're involved in. We seem to be spending almost as much time dealing with the financial side of the project as we are with the instructional design side. (Hero)

I did a complete degree in instructional technology, and I never once got a course or even a part of a course on budgeting, financial management, actually costing out a project. That's all part of the instructional design process. As an instructional designer, I have to be the project manager. At the end of the day, somebody has to say, "This got done." (Dijan)

Some of the project management skills that seem to fall to the instructional designers we interviewed were even more tedious and less glamorous than financial management. Several reported having to manage routine office duties in addition to carrying out menial technical course support activities. While there was some resentment evident in their comments, instructional designers seemed to indicate that they were in positions where they had few options. While dedication to the completion of a project is understandable, their resentment reveals a deeper concern that their position is neither understood nor respected.

I am also assigned minor detail duties that really the front office staff could do easily such as filing, mailing, etc. and would be more valuable use of my time to do other things they cannot. (Lab)

I end up doing a lot of maintenance on non-course specific web pages simply because I can and I don't like telling academics when they ask me to make corrections that that isn't my job. (Rod)

Academics view us as 'techies' or 'computer jocks' while those folks in the Computing Services or Systems Analyst camps view us as 'artsy' and 'trouble' and 'those people who keep asking for things we don't want to give'. So to the academics I'm responsible to at the moment I'm the face of technology (many of them are technophobes) and to computing services I'm someone who makes their lives a bit more difficult because I need access or something installed on the server. (Rod)

\section{Institutional Roles}

In order to promote or raise the profile of instructional design, practitioners are required to educate colleagues about the practices and contributions of instructional design. This seems to be a necessary task, not just to maintain a professional profile, but often to preserve the practice of ID in the institution. Instructional design is also seen as playing a systemic design role in post- 
secondary learning, responding to the challenges of strategic change (Rowland, 2006). Educating colleagues and central administration about the professional practice of instructional design is delicate, given fiscal challenges in higher education, but attending to this part of the job was identified as important by the participants in this study.

To explain not only what ID is, but also why it is important, why it's critical, why it's a cornerstone of activity in terms of improvement of pedagogy, teaching and learning to a wider audience. So, committees that I've sat on, sometimes not even directly related to teaching and learning - but even peripherally, I've had to make those kinds of arguments, descriptions-support for the idea. So in a sense you might even call it marketing for the idea of instructional design and its importance. And I enjoy doing that. I mean, I don't shrink from the challenge of telling someone or even a large group of people why I think instructional design is very, very important. (Dimo)

Designers suggested that reputation is built over time, given the success of instructional design projects. This is useful when projects are successful, but it also points to a general sense that instructional designers feel that they are required to prove their worth in an environment they cannot control, and where their contributions are not sufficiently acknowledged. Instructional design was reported to be a shadow profession, one that clients appreciate from experience, but which carries little weight in the way of anticipation by the client. As a result, instructional designers suggested they needed to assume the role of evangelist for the profession, a role that had beneficial and difficult aspects.

Once the project is going well, then you find that the SME wants to take it down the hall and show it to their buddies in the department. Well then, "come with me. You've got to show them that they can do some of these neat things too," and you become the evangelist for this particular kind of project. And that sometimes sparks a little community of practice where there are four or five people in a college or a department that all want to get involved, that all want to get on this. (Gap)

It combines those things, beliefs and passions, what he or she believes in, but is also diplomatic about it. A poor evangelist would shove the dogma down someone's throat and cause a repulsive reaction. So I've had to exercise diplomacy with SMEs who not only don't understand what an objective is, but reject the notion outright. What do you do then? Then you need to exercise some diplomacy and work more carefully and cautiously with that person. (Dimo)

Promotion or defense of the profession requires tact, intuition, and sensitivity. Diplomacy was described as a difficult and vital skill for instructional designers, and yet it is a skill that is required only through experience, rather than in professional training. 
Another role I take on as an ID, that for me, is probably the most difficult that of diplomat. As often as I'm tempted to say what I'm thinking, I'm learning to "couch" things so they smooth egos and keep the peace. SMEs who ignore my requests for content or review, graphic artists who think the world revolves around them, departments who lay off SMEs in the middle of course development and don't answer questions as to how this might affect course development...my tongue has grooves in it! (Shap)

I seem to be spending time on is putting out fires around issues of professionalism and old wounds. (Hero)

As one member or leader of a team the instructional designer must juggle the egos and expectations of administrators, clients, instructors, and even students. Everyone on a project has a vested interest in its success but individuals may also have large investments in content, reputation, or budget. The ability to anticipate conflicts around these issues can be a great asset, and requires the deft touch of a skilled politician.

One of the roles I see instructional designers have that is critical on a university campus is the political role, and you've just pointed to it. There is a whole range of political knowledge, political processes that you need to have, and political action you have to take to exercise your instructional design role. But in this institution, if you're not aware of the politics of the various tiers of organizations and sub-institutions, you're dead. (Dimo)

\section{Teaching and Learning Roles}

For some instructional designers, learning about a new topic or area of study is the most interesting part of what they do. Again, IBSTPI (2000) standards address learning, but in this case the standards seem to be confined to professional development and maintenance of currency by instructional designers. In this case, our participants approached teaching and learning issues differently-as opportunities for personal growth and for indoctrinating clients in the language and peculiarities of instructional design. Several of the participants indicated that they are insatiable learners, and they enjoy being permitted to infiltrate other professions and get an intimate glimpse of unfamiliar content. This 'expert for a day' opportunity also challenges instructional designers to reflect on their own philosophies of teaching and learning, to situate their own professional identities in an array of contexts.

To some extent, instructional designers have to be incredibly self-aware of their own teaching philosophy and their own biases. Because if you're not aware what you come to the table with, you're not willing to listen to what the instructor wants to bring to the process as well. (Dijan)

I need to be the learner before there are any actual learners. I act as a proxy, as a naïve but interested consumer of the discipline. (Jam) 
The clients with whom instructional designers work often have deep knowledge of their disciplines but little or no training as educators. As a result, instructional designers reported that they spent considerable time and effort acquainting clients with the language and psychology of learning and pedagogy, and sometimes, instructors overlook the rudiments of teaching.

I've found that so many of the instructors I've worked with, who are highly renowned instructors in their fields, don't know the language of pedagogy. You start talking about what your pedagogical design strategy is, and they say, "What? How do you spell that? What does that mean? (Gap)

Despite a general lack of understanding of, and sometimes appreciation for, teaching and learning, instructional designers find themselves in learning cultures that are deeply entrenched in a particular approach to teaching and learning. These are often tenaciously held belief systems, and they differ from one academic discipline to another. The variety of cultures requires the instructional designer to adapt to dramatically different contexts, and to align designs with the prevailing culture of the discipline.

The thing is learning these cultures...I'd go from Engineering to Dentistry to Education to Vet Med and I was just shaking my head. What I had to learn, over time, was the culture in the College in the Academy - there is a pedagogical culture that is strong. (Gap)

You have to learn that there's a polyculture here of pedagogy. You've got to have your sensors out, so when it's time to rip off the cognitivist hat and it's time to put on the constructivist hat so that you don't have any personal conflicts happening. (Gap)

Ultimately, instructional designers draw considerable satisfaction from being change agents (Campbell, Schwier, \& Kenny, 2009). They consider themselves responsible for institutional, as well as professional, transformation. Trying to change an entire institution is challenging and frustrating, but instructional designers reported that it is also an important part of their work. They are advocates for promoting good teaching, good learning, and ultimately contributing to the professional development of instructors over an extended period of time.

It's fundamentally taking an individual-an instructional designer-throwing them into a lake, and expecting the lake to transform. The lake is the institution, the College, the individuals...all levels. To some extent, you can do instructional design without ever having been thrown in the lake, without ever trying to do any transformation; but the really good stuff, the stuff that gets talked about, the stuff that changes a student's life, the stuff that changes a faculty member's life, happens when you break through those barriers. (Dijan) 


\section{Conclusions}

Based on what we heard from the participants in this study, instructional design is not a narrowly defined job, nor a matter of following a process or even inventing a process for completing a complex task. Instructional designers in post-secondary education carry out a wide range of roles, all of which emphasize complex interactions among individuals who are navigating an equally complex institution. Instructional designers are expected to have a wider range of skills and abilities than are typically taught in instructional design programs (Williams vanRooij, 2009).

This investigation reinforced an idea that is not unique to instructional design: professional practitioners face a wide range of demands, and these demands are often outside the boundaries of what we think of as "instructional design". While there is little likelihood that instructional design programs will be able to directly address everything that a new practitioner needs, we suspect that programs that emphasize experiential learning will be successful in introducing instructional designers to authentic problems and contexts, and help new practitioners begin to understand the rich and complex careers they are entering. Graduate programs in instructional design are responding to this challenge and experimenting with novel approaches (Boling, et al., 2009; Correia et al., 2010).

An interesting speculation we drew from this investigation was that practitioners of instructional design might be carrying unrealistically narrow definitions of their roles into their careers. If instructional designers, or any professionals in complex careers for that matter, expect their training to embrace everything they will need to practice ID, then perhaps enlightening them to the vagaries of ID is just as important as any specific content or skill. We were struck by how many of the items identified by participants as "not part of ID" were in fact things we considered as routine dimensions of instructional design, or skills we would expect instructional designers to have, or that were identified in the literature as important issues in instructional design.

This begs several questions. How should the professional education of instructional designers be shaped to meet the demands faced by practitioners? How can programs be shaped to respond to a wider range of demands than can be confined by a curriculum? Should selection processes for instructional design programs include an expanded range of admission criteria? Would more or different people be interested in a career in instructional design if they were aware of the diverse nature of the work?

While these are questions worth pondering, we also suggest that following up on this research can contribute to our understanding of what it means to be an instructional designer. We suggest that it is worthwhile to replicate this work to see whether the categorizations of professional relationship roles, project roles, institutional roles, and teaching and learning roles are robust, and to discover what other categories of activity exist. It is also worth examining these questions in different settings. This study was confined to instructional designers in post-secondary education, and it is possible that different tensions are evident in business and industry, government, or other educational contexts. 


\section{References}

Boling, E., Gibbons, A., Ertmer, P., Schwier, R. Wilson, B., \& Wilson, J. (2009, April) How are designers taught to do what they do? Multiple approaches to masters-level design education. Special panel and poster sessions American Educational Research Association (AERA) Conference, San Diego, CA.

Brill, J., Bishop, M., \& Walker, A. (2006). The competencies and characteristics required of an effective project manager: a web-based Delphi study. Educational Technology Research and Development, 54, 2, 115-140.

Campbell, K., Schwier, R., \& Kenny, R. (2009). The critical, relational practice of instructional design in higher education: An emerging model of change agency. Educational Technology Research and Development, 57(5), 645-664.

Correia, A., Yusop, F., Wilson, J., \& Schwier, R. (2010, April). A comparative case study of approaches to authentic learning in instructional design at two universities. American Educational Research Association, Denver, Colorado.

Cox, S. \& Osguthorpe, R. (2003, May / June). How do instructional design professionals spend their time? TechTrends, 47(3), 45-47, 29.

Dick, W. ,Carey, L., \& Carey, J. (2009). Systematic design of instruction ( $7^{\text {th }}$ ed.). Toronto: Allyn \& Bacon.

Dooley, K., Lindner, J., Telg, R., Moore, L., Lundy, L., \& Irani, T. (2007). Road map to measuring distance education instructional design competencies. Quarterly Review of Distance Education, 8(2), 151-159.

Gibbons, A. (2003, September / October). What and how do designers design: A theory of design structure. TechTrends, 47(5), 22-27.

Greer, M. (1994). ID project management, Tools and techniques for instructional designers and developers ( $2^{\text {nd }}$ ed.). Englewood Cliffs, NJ: Educational Technology Publications.

Gustafson, K., \& Branch, R. (2002). What is instructional design? In R.A. Reiser, \& J.V. Dempsey (Eds.). Trends and issues in instructional design and technology (pp. 16-25). Upper Saddle River, NJ: Merrill Prentice Hall.

IBSTIPI (2000). Instructional design competencies. State College, PA: International Board of Standards for Training, Performance and Instruction. Retrieved from http://www.ibstpi.org/downloads/InstructionalDesignCompetencies.pdf and http://www.scribd.com/doc/25348521/IBSTPI-Standards-for-Instructional-Design

Jonassen, D., Boling, E., Gibbons, A., Parrish, P., \& Schwier, R. (2008, November). Design is not systematic: Alternative perspectives on design. Annual conference of the Association for Educational Communications and Technology, Orlando, Florida, November 4-8.

Kenny, R., Zhang Z., Schwier, R., \& Campbell, K. (2005). A review of what instructional designers do: Questions answered and questions not asked. Canadian Journal of Learning and Technology, 31(1). 9-26. 
Morrison, G., Ross, S., \& Kemp, J. (2010). Designing effective instruction (6 $6^{\text {th }}$ ed.). Toronto: Wiley.

Richey, R., Fields, D., \& Foxon, M. (with Roberts, R., Spannaus, T., \& Spector, J.M.) (2001). Instructional design competencies: The standards ( $3^{\text {rd }}$ ed.). Syracuse, NY: ERIC Clearinghouse on Information and Technology (ED453803).

Rowland, G. (1992). What do instructional designers actually do? An initial investigation of expert practice. Performance Improvement Quarterly, 5(2), 65-86.

Rowland, G. (2006). Systems designing: Responding to the limitations of strategic planning. Educational Technology, 46(2), 7- 10.

Schwier, R., Campbell, K., \& Kenny, R. (2007). Instructional designers' perceptions of their interpersonal, professional, institutional and societal agency: Tales of change and community. In M. Keppell (Ed.), Instructional design: Case studies in communities of practice (pp. 1-18). Hershey, PA: Idea Group.

Smith, P. L., \& Ragan, T. J. (2005). Instructional design ( $3^{\text {rd }}$ ed.). Toronto: Wiley.

Solomonson, W.L. (2008). Toward fluent instructional design in the context of people. Performance Improvement, 47(7), 12-19.

Spector, J., Klein, J., Reiser, R., Sims, R., \& de la Teja, I. (2006, April). Competencies and standards for instructional design and educational technology discussion paper for ITFORUM, 17-21.

Williams vanRooij, S. (2009). Project management in instructional design: ADDIE is not enough. British Journal of Educational Technology. Retrieved from http://www3.interscience.wiley.com/cgi-bin/fulltext/122473190/PDFSTART.

Correspondence: Richard A. Schwier, Professor, Curriculum Studies, College of Education, University of Saskatchewan, 28 Campus Dr., Saskatoon, SK. S7N0X1, Canada. 